\title{
EXTRAÇÃo EM FASE SÓLIDA (SPE) E MICRO EXTRAÇÃo EM FASE SÓLIDA (SPME) DE PIRETRÓIDES EM ÁGUA
}

\author{
Wilma Regina Barrionuevo e Fernando Mauro Lanças* \\ Instituto de Química de São Carlos, Universidade de São Paulo, CP 780, 13560-970 São Carlos - SP
}

Recebido em 18/10/99; aceito em 11/10/00

\begin{abstract}
SOLID-PHASE EXTRACTION (SPE) AND SOLID-PHASE MICROEXTRACTION OF PYRETHROIDS IN WATER. The pyrethroids bifenthrin, permethrin, cypermethrin and deltamethrin were extracted by solid phase extraction (SPE) and solid phase microextraction (SPME). The analysis were performed on a gas chromatograph with electron capture detection (GC-ECD). Octadecil Silano- ${ }_{18}$, Florisil and Silica stationary phases were studied for SPE. Better results were obtained for Florisil which gave recoveries from $80 \%$ to $108 \%$. Pyrethroids extraction by SPME showed a linear response and a detection limit of $10 \mathrm{pg} \mathrm{ml}^{-1}$. Although the data showed that the two extraction methods were able to isolate the pesticide residues from water samples, the best results were obtained by using SPME which is more sensitive, faster, cheeper, being a more useful technique for the analysis of pyrethroids in drinking water.
\end{abstract}

Keywords: water analysis; pyrethroids; solid-phase extraction; solid-phase microextraction.

\section{INTRODUÇÃO}

Piretróides são inseticidas de origem vegetal, obtidos da trituração das flores de algumas plantas pertencentes ao gênero Chrysanthemum. Estes compostos apresentam amplo espectro de atividade, ação rápida, eficiência em pequenas doses, baixo poder residual e, adicionalmente, são praticamente atóxicos para mamíferos, quando comparados a outros inseticidas ${ }^{1}$.

Apesar da baixa toxicidade verificada para mamíferos, estudos toxicológicos muito recentes com 243 pesticidas mostraram que os piretróides estão entre os pesticidas mais tóxicos para organismos aquáticos, tais como peixes e crustáceos ${ }^{2}$. São, ainda, altamente tóxicos para abelhas ${ }^{3}$. Assim, o uso indiscriminado de piretróides pode afetar drasticamente o equilíbrio já precário no meio ambiente, requerendo seu monitoramento, através de análises de seus resíduos em diversas fontes de água.

Os métodos de extração e clean-up de piretróides em alimentos e amostras ambientais foram revistos e sumarizados recentemente por Papadopoulou-Morkidou ${ }^{4}$. A extração destes compostos é relativamente simples, quando comparada com a de outros pesticidas, devido à sua baixa polaridade.

Dentre as técnicas de extração normalmente utilizadas para concentrar analitos, destacam-se a extração líquido-líquido (LLE), a extração com fluido supercrítico (SFE), a extração em fase sólida (SPE) e, mais recentemente, a micro extração em fase sólida (SPME).

A SPE é uma das técnicas de extração mais utilizadas. Nesta técnica, os analitos contidos numa matriz aquosa são extraídos, juntamente com os compostos interferentes, após passarem por um cartucho contendo sorvente. Um solvente orgânico seletivo é geralmente utilizado para remover os interferentes e então, outro solvente é usado para lavar os analitos de interesse. Apesar da SPE apresentar vantagens com relação aos métodos mais clássicos, tais como praticidade e maior sensibilidade, esta técnica tem algumas limitações. Uma delas refere-se à etapa de dessorção do analito aprisionado no cartucho de SPE que requer geralmente, o uso de solventes tóxicos.

A SPME, promissora técnica de extração, encontra-se ainda em fase de desenvolvimento e baseia-se originalmente na adsorção dos analitos em uma fibra de sílica coberta com uma camada de sorvente (Figura 1). A fibra é introduzida diretamente na amostra aquosa e, por partição, concentra o analito em sua superfície (sorvente). Posteriormente, os analitos são dessorvidos termicamente em um cromatógrafo a gás. É um método rápido, que não requer o uso de solventes ${ }^{5-10}$.

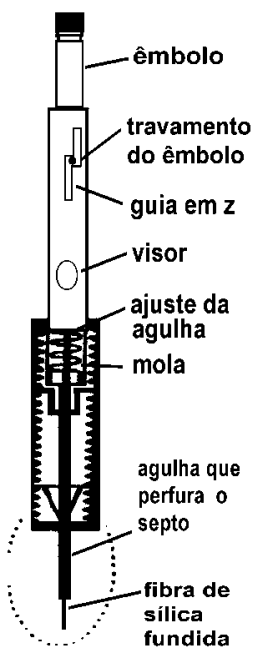

Figura 1. Dispositivo utilizado em micro extração em fase sólida (SPME) (modificado de Graham et al. ${ }^{12}$ ).

A SPME preserva todas as vantagens da SPE, tais como simplicidade, baixo custo, fácil automação, e facilidade de amostragem em campo e, ao mesmo tempo, elimina desvantagens da SPE, tais como o entupimento do cartucho e o uso de solventes.

Para análise de piretróides, vários trabalhos foram realizados utilizando-se $\mathrm{LLE}^{2,4}$ e, mais recentemente $\mathrm{SPE}^{4,11}$. Nenhum artigo foi encontrado sobre análise de piretróides por SPME. Trabalho recente, apresentado por Barrionuevo e Lanças ${ }^{5}$ em reunião científica, mostra um limite de detecção de $10 \mathrm{pg} \mathrm{ml}^{-1}$, para piretróides extraídos por SPME, indicando o excelente limite de detecção (LOD) desta técnica na análise de piretróides, quando comparado às demais técnicas citadas.

O objetivo do presente trabalho consiste na comparação da eficiência e praticidade das técnicas de extração SPE e SPME, na análise de piretróides em água.

\section{PARTE EXPERIMENTAL}

\section{Material}

Foram utilizados os padrões analíticos bifentrina, cipermetrina, deltametrina e permetrina, obtidos da Accustandard (USA). 


\section{Técnicas de extração}

Micro extração em fase sólida

Para o preparo da solução concentrada, foram diluídas 10 mg dos piretróides bifentrina, cipermetrina, permetrina e deltametrina em $10 \mathrm{ml}$ de etanol (concentração: $1000 \mu \mathrm{g} \mathrm{ml}^{-1}$ ). Foram preparadas então, as soluções de trabalho, diluindo-se a solução concentrada em água e obtendo-se concentrações entre $1 \mu \mathrm{g} \mathrm{ml}^{-1}$ e $1 \mathrm{pg} \mathrm{ml}^{-1}$.

Para a extração dos analitos, a fibra de SPME foi introduzida em um frasco de vidro, contendo em seu interior a solução com os piretróides e um pequeno imã para auxiliar na agitação da solução durante o processo de extração. O frasco foi então colocado na superfície de um sistema de agitação magnética (agitador marca Corning, USA) e a temperatura da solução foi mantida constante $\left(30^{\circ} \mathrm{C}\right)$.

Após o período de 40 minutos de exposição às soluções de piretróides, a fibra foi imediatamente introduzida no injetor do cromatógrafo à gás, conectado a um detector de captura de elétrons-ECD. O período de dessorção térmica foi de $14 \mathrm{minu}-$ tos, após o qual a fibra foi retirada do injetor. Os valores obtidos em cada concentração foram lançados em gráfico e, após feita a regressão linear, foi calculado o coeficiente de correlação $r$ para cada reta. Foram feitas 3 injeções para cada concentração estudada. As etapas básicas de extração por SPME estão descritas na Figura 2.

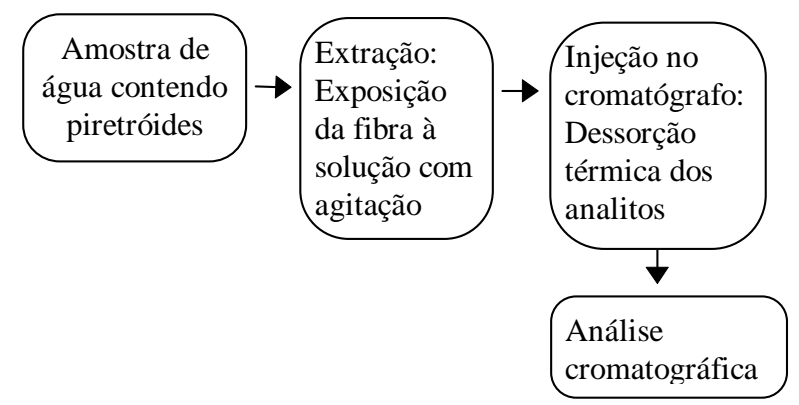

Figura 2. Etapas básicas da análise de piretróides em água por SPME e cromatografia.

\section{Extração em fase sólida (SPE)}

Foram realizadas comparações na capacidade de extração de diferentes sorventes (Florisil, Octadecil Silano- $\mathrm{C}_{18}$ e Sílica), contidos separadamente em cartuchos de SPE $(1 \mathrm{~g}$ de sorvente para cada cartucho). $\mathrm{O}$ procedimento para a extração das amostras de água Milli-Q enriquecidas com piretróides em diferentes concentrações $\left(0,01 ; 0,05 ; 0,1 ; 0,5\right.$ e $\left.1 \mu \mathrm{g} \mathrm{ml}^{-1}\right)$, é ilustrado na Figura 3. Foram calculadas as porcentagens de extração dos piretróides, em diferentes concentrações, para cada sorvente estudado e preparadas 3 replicatas para cada diferente concentração.

Comparação entre o volume de amostra e no tempo de extração requerido para as técnicas SPME e SPE

O limite de detecção dos piretróides (bifentrina, cipermetrina, permetrina e deltametrina), por injeção direta no cromatógrafo, sem pré-concentração, foi verificado como sendo de $0,5 \mu \mathrm{g} \mathrm{ml}^{-1}$. Assim, na técnica de SPE, é necessário que a concentração final da amostra a ser injetada no cromatógrafo, após extração e nas mesmas condições de análise, seja igual ou superior a $0,5 \mu \mathrm{g} \mathrm{ml}^{-1}$.

Para efeito comparativo, 1 litro de água foi enriquecido com piretróides, obtendo-se uma concentração de $1 \mathrm{ng} \mathrm{ml}^{-1}$. Calculou-se, então, qual o volume necessário para que a concentração final da amostra extraída por SPE fosse igual ou superior a 0,5 $\mu \mathrm{g} \mathrm{ml}^{-1}$, e o tempo necessário para a passagem desta amostra pelo cartucho de SPE, preparado com $1 \mathrm{~g}$ de florisil (sorvente).

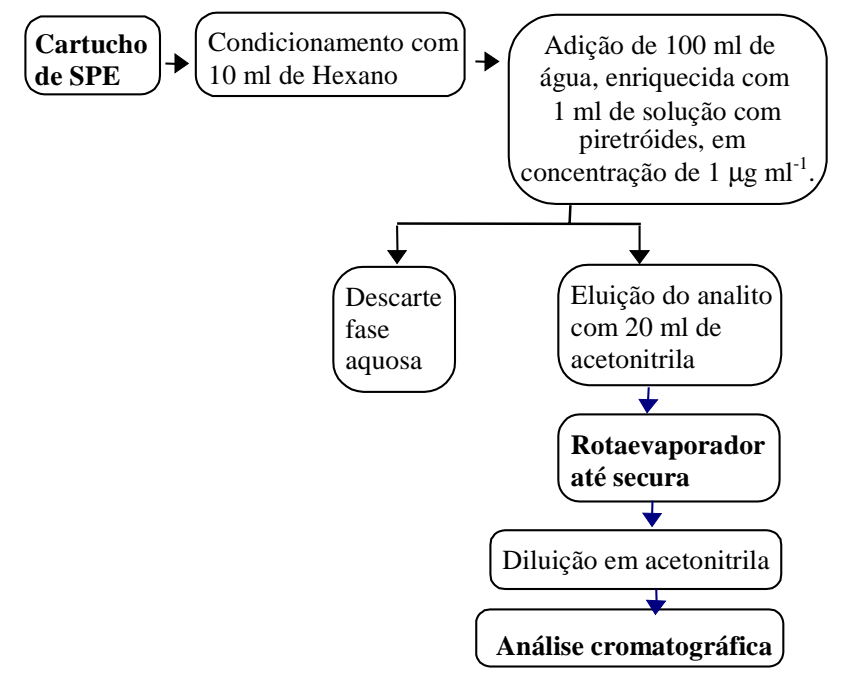

Figura 3. Etapas básicas da análise de piretróides em água por SPE e cromatografia

Para análise por SPME, foram utilizados $5 \mathrm{ml}$ da solução de piretróides, na mesma concentração acima. Após a introdução da fibra no frasco, a amostra foi agitada por 5, 10, 15 ou 20 minutos e a fibra foi, então, levada ao cromatógrafo para análise. Para efeito comparativo, determinou-se o tempo de extração, após o qual foram obtidos cromatogramas com as áreas semelhantes às obtidas na extração por SPE, partindo-se da amostra de mesma concentração $\left(1 \mathrm{ng} / \mathrm{ml}^{-1}\right)$. Foram feitas 3 replicatas para cada tempo de extração.

Análises estatísticas

As análises estatísticas do presente trabalho (Kruskal-Wallis ANOVA e Student Newman Keuls -NKS), para o cálculo da regressão linear e do coeficiente de correlação entre os piretróides, foram realizadas através dos programas computacionais Sigma Stat, versão 1.0, Jandel Corporation e Statigraphics, versão 5.0, ambos para Microsoft Windows.

\section{RESULTADOS E DISCUSSÃO}

Micro Extração em Fase Sólida - SPME

\section{Curvas analiticas}

A SPME é uma técnica rápida, sensível, barata, portátil e dispensa o uso de solventes ${ }^{6-11}$. Os resultados encontrados para os piretróides bifentrina, permetrina, cipermetrina e deltametrina no presente trabalho mostram elevada correlação entre as concentrações das amostras e as áreas obtidas (Figura 4), com coeficientes de correlação de cada uma das curvas dos piretróides sendo maior do que 0.99 para todos os compostos, exceto para a cipermetrina cujo coeficiente foi de 0.98 .

\section{Extração em Fase Sólida- SPE}

A obtenção de resultados satisfatórios na extração de piretróides requer alguns cuidados, devido à baixa solubilidade destes compostos em solventes polares (orgânicos). Van der Hoff et al. $^{2}$ mostraram que as porcentagens de extração por SPE dependem dos solventes utilizados antes e depois da passagem da amostra pelo cartucho. Aparentemente não existe um padrão de solventes a ser utilizado na extração de piretróides por SPE, pois os procedimentos variam bastante. No presente trabalho optou-se por hexano e acetonitrila, utilizados na maioria dos trabalhos com estes compostos ${ }^{4,7-10}$. 
Tabela 1. Porcentagem de recuperação de piretróides, após extração com SPE, utilizando diferentes sorventes (Octadecil Silano$\mathrm{C}_{18}$, Florisil e Sílica Gel). (n/d: não detectado)

\begin{tabular}{|c|c|c|c|c|c|c|}
\hline \multirow{2}{*}{$\begin{array}{c}\text { Concentração } \\
\text { ppm }\end{array}$} & \multicolumn{3}{|c|}{ Bifentrina } & \multicolumn{3}{|c|}{ Permetrina } \\
\hline & $\mathrm{C}_{18}$ & Florisil & Sílica & $\mathrm{C}_{18}$ & Florisil & Sílica \\
\hline 0,01 & $85,2 \pm 1,9$ & $108,2 \pm 12,4$ & $87,8 \pm 13,6$ & $87,6 \pm 1,3$ & $92,9 \pm 1,4$ & $90,0 \pm 4,7$ \\
\hline 0,05 & $83,9 \pm 5,9$ & $93,7 \pm 4,6$ & $89,0 \pm 3,8$ & $90,9 \pm 0,6$ & $103,9 \pm 1,9$ & $93,3 \pm 0,7$ \\
\hline 0,10 & $92,8 \pm 5,2$ & $103,0 \pm 4,8$ & $92,5 \pm 2,1$ & $90,1 \pm 4,7$ & $107,3 \pm 0,4$ & $93,9 \pm 1,3$ \\
\hline 0,50 & $78,4 \pm 6,1$ & $102,1 \pm 1,7$ & $88,1 \pm 3,2$ & $98,1 \pm 0,5$ & $98,8 \pm 0,5$ & $78,8 \pm 0,4$ \\
\hline 1,00 & $84,2 \pm 3,4$ & $106,4 \pm 4,6$ & $74,4 \pm 1,4$ & $106,9 \pm 0,4$ & $99,7 \pm 0,4$ & $76,4 \pm 0,3$ \\
\hline Concentração & & Bifentrina & & & Permetrina & \\
\hline ppm & $\mathrm{C}_{18}$ & Florisil & Sílica & $\mathrm{C}_{18}$ & Florisil & Sílica \\
\hline 0,01 & $\mathrm{n} / \mathrm{d}$ & $\mathrm{n} / \mathrm{d}$ & $\mathrm{n} / \mathrm{d}$ & $\mathrm{n} / \mathrm{d}$ & $\mathrm{n} / \mathrm{d}$ & $\mathrm{n} / \mathrm{d}$ \\
\hline 0,05 & $\mathrm{n} / \mathrm{d}$ & $\mathrm{n} / \mathrm{d}$ & $\mathrm{n} / \mathrm{d}$ & $\mathrm{n} / \mathrm{d}$ & $\mathrm{n} / \mathrm{d}$ & $\mathrm{n} / \mathrm{d}$ \\
\hline 0,10 & $72,8 \pm 2,1$ & $96,3 \pm 12,5$ & $85,9 \pm 2,5$ & $71,2 \pm 1,0$ & $81,3 \pm 10,5$ & $61,5 \pm 1,8$ \\
\hline 0,50 & $82,2 \pm 2,5$ & $83,9 \pm 1,4$ & $85,2 \pm 3,1$ & $80,1 \pm 2,4$ & $95,9 \pm 1,6$ & $53,4 \pm 1,9$ \\
\hline 1,00 & $87,0 \pm 1,5$ & $87,0 \pm 3,8$ & $97,9 \pm 1,9$ & $83,4 \pm 3,2$ & $91,6 \pm 4,0$ & $72,4 \pm 1,4$ \\
\hline
\end{tabular}

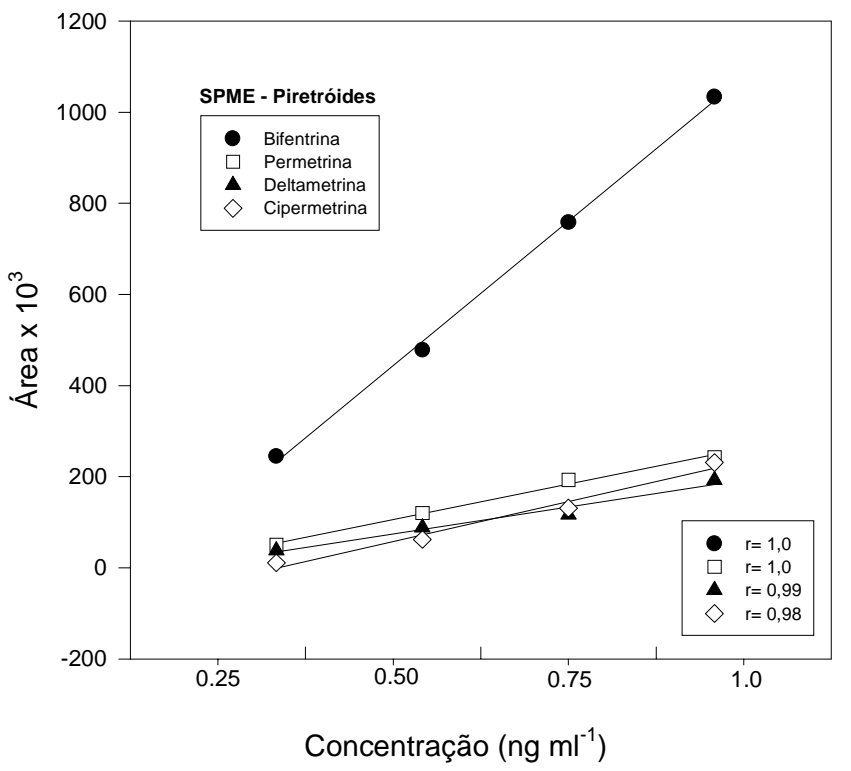

Figura 4. Representação gráfica das curvas analíticas de piretróides, em extração de piretróides por SPME. Fibra de $100 \mu \mathrm{m}$ de polidimetilsiloxano (PDMS).Temperatura: $30^{\circ} \mathrm{C}$. Tempo de agitação: 40 minutos.

Na Figura 5 são apresentadas as curvas analíticas de piretróides, extraídos por SPE, utilizando-se cartuchos com diferentes sorventes $\left(\mathrm{C}_{18}\right.$, Florisil e Sílica). As porcentagens de recuperação dos compostos em cada sorvente são mostradas na Tabela 1 onde verifica-se de um modo geral, uma boa correlação entre as concentrações dos analitos e as áreas dos picos. A porcentagem de recuperação dos piretróides $(53,4 \%$ a $108,2 \%$ ) foi semelhante à encontrada em alguns trabalhos descritos na literatura ${ }^{8,10}$ e pode ser considerada satisfatória, considerando que apenas 2 valores estiveram abaixo de $70 \%$, o que mostrou uma menor resposta da deltametrina ao sorvente sílica. As diferenças de extração entre os 3 sorventes testados $\left(\mathrm{C}_{18}\right.$, Florisil e Sílica), foi significativa (teste de KruskalWallis) e mostrou maior eficiência de extração quando utilizou-se florisil. Os valores obtidos para o $\mathrm{C}_{18}$ e sílica foram, no entanto, apenas ligeiramente inferiores, o que indica que estes sorventes também poderiam ser utilizados, e que com o uso de outros solventes, possam apresentar melhor eficiência.

Na Tabela 2 verificam-se os valores da extração de uma solução de $1 \mu \mathrm{g} \mathrm{ml}^{-1}$ da mistura de piretróides, por SPME e por SPE. Observa-se que partindo-se desta mesma solução, o

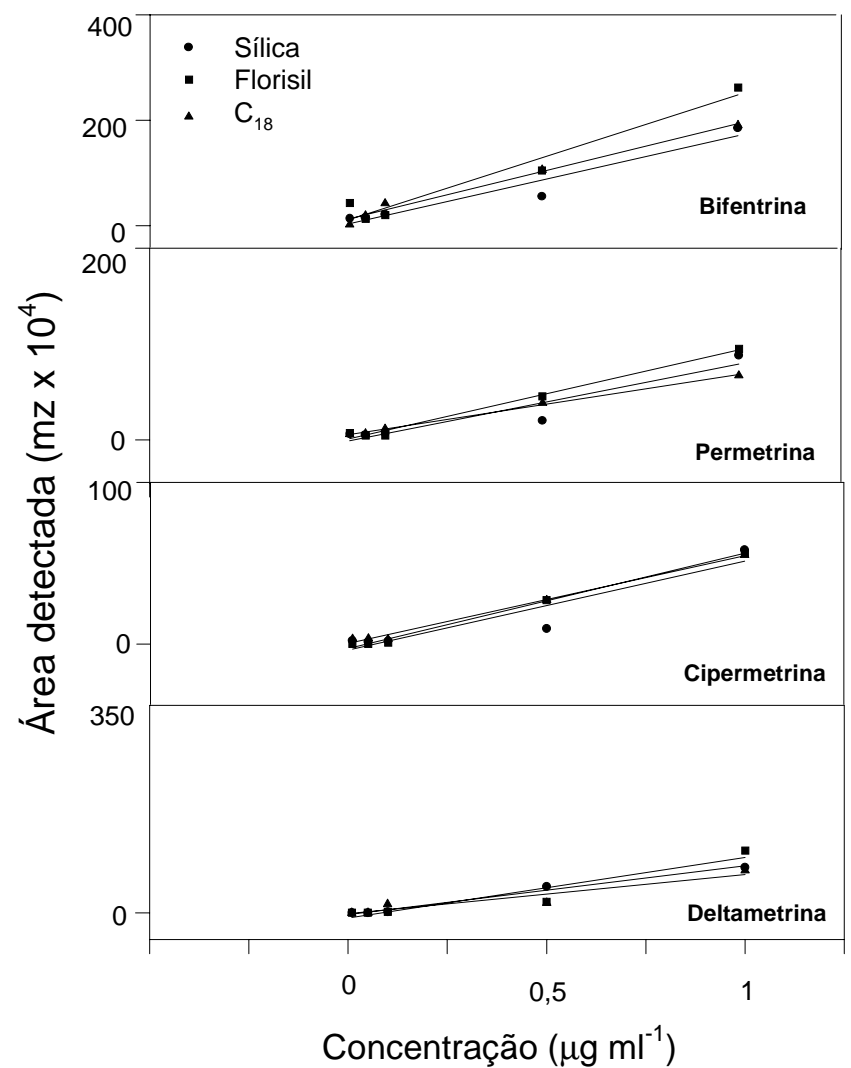

Figura 5. Curvas analíticas de diferentes piretróides, após extração por SPE, utilizando-se diferentes sorventes.

volume de amostra e, consequentemente, o tempo de extração necessário, foi bastante superior na SPE, para a obtenção de cromatogramas de áreas semelhantes (Figura 6). Além disso, na SPE utilizou-se solventes tóxicos, os quais não foram necessários na SPME.

Tabela 2. Volume da amostra e tempo de extração de uma solução de $0,5 \mathrm{ng} \mathrm{ml}^{-1}$ de piretróides, por microextração em fase sólida (SPME) e por extração em fase sólida (SPE).

\begin{tabular}{lcc}
\hline & SPME & SPE \\
\hline Volume utilizado $(\mathrm{ml})$ & 5 & 500 \\
Tempo de extração $(\mathrm{h})$ & $0: 10$ & $2: 18 \pm 0: 12$ \\
\hline
\end{tabular}




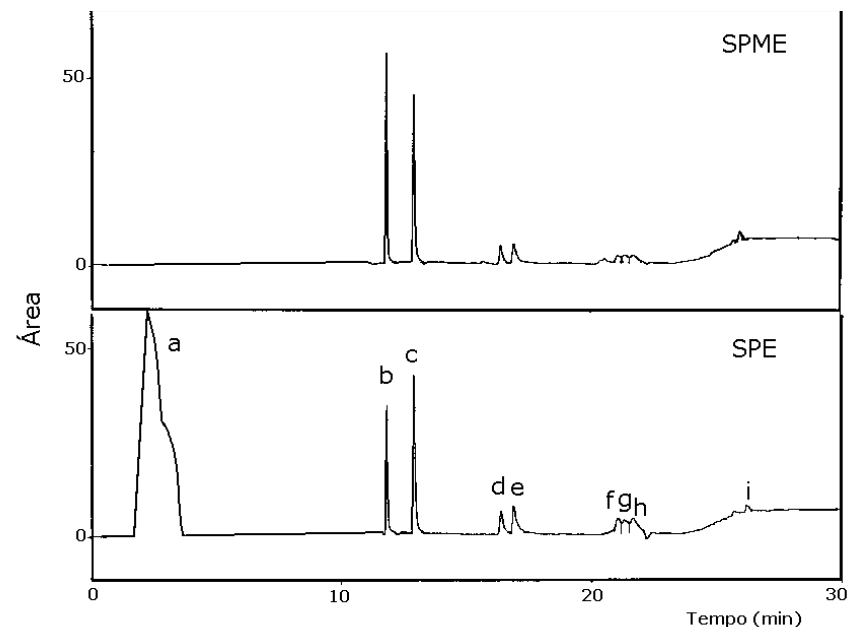

Figura 6. Cromatograma de piretróides extraídos por SPME e por SPE. a: pico dos solventes; b e c: bifentrina; d e e: permetrina; $\mathrm{f}, \mathrm{g}$ $e$ h: cipermetrina e i: deltametrina.

Comparando-se com a SPME, a SPE é muito mais demorada e é notório o custo ambiental e econômico mais elevado, devido ao descarte de solventes e ao tempo de extração da amostra.

\section{CONCLUSÕES}

Estudaram-se dois procedimentos de extração para a análise de piretróides em água: a extração em fase sólida (SPE) e a micro extração em fase sólida (SPME). Na primeira, SPE, os resultados obtidos neste trabalho foram similares a outros descritos na literatura e considerados satisfatórios. Comparando-se porém, ambas as técnicas, a SPME mostrou-se mais prática e rápida e, portanto, mais adequada para a análise de piretróides em água, particularmente em amostras com baixas concentrações destes analitos.

\section{AGRADECIMENTOS}

Os autores agradecem à FAPESP ( Proc. 96/9269-5 e 98/ 04017-3), pelo suporte financeiro recebido, ao prof. Dr. Emanuel Carrilho pelas sugestões dadas e ao Dr. Marco A. Barbirato e à Mestre Elaine A.A.F. Gobato pelo auxílio na parte experimental do trabalho.

\section{REFERENCIAS}

1. Hirata, R.; Quim. Nova 1995, 18, 368.

2. Hoff, G. R. Van der; Pelusio, F.; Brinkman, U. A.Th.; Baumann, R. A.; Zoonen, P.; J. Cromatogr. A 1996, $719,59$.

3. Galera, M. M.; Vidal, J. L. M.; Frenich, A. G.; Garcia M. D. G.; J. Chromatogr. A 1996, 727, 39.

4. Papadopoulou-Morkidou, E.; In: Compreensive Analytical Profile of Important Pesticides; Sherma, J., Caines,T. ; Ed.; CRC Press, New York, 1993, p.146.

5. Barrionuevo, W. R.; Lanças, F. M. $1^{\circ}$ Seminário Nacional sobre Monitoramento de Resíduos de Agrotóxicos, Ribeirão Preto. 1999.

6. Nam, K. S.; King, J.; J. High Resol. Chromatogr. 1994, 17, 577.

7. Martos, P.; Pawliszyn, J.; Seventh Latin American Congress on Chromatography - RESUMOS, Águas de São Pedro, SP., Brasil, 1998, p.31.

8. Pang, G. F.; Chao, Y. Z.; Fan, C. L.; Zhang, J. J.; Li, X. M.; Liu, Y. M.; J. AOAC Int. 1995, 78, 1989.

9. Eisert, R.; Pauliszyn J.; J. Chromatogr. 1997, 776, 293.

10. Pappilloud, S.; Haerd, W.; Chiron, S.; Barceló, D.; Environ. Sci. Technol. 1996, 30, 1822.

11. Chen, Z. M.; Wang, Y. H.; J. Chromatogr. A 1996, $754,367$.

12. Graham, K. N.; Sarna, L. P.; Webster, G. R. B.; Gaynor, J. D. and Ng, H. Y. F.; J. Chromatogr. A 1996, 725, 129. 